\title{
Pensamento Empreendedor, uma Alternativa para a Internalização do Empreendedorismo
}

\author{
Entrepreneurial Thinking, an Alternative to the Internalization of \\ Entrepreneurship
}

\author{
Sônia Marise Salles Carvalho ${ }^{1}$ \\ Adriana Regina Martin ${ }^{1}$ \\ Agnaldo Almeida Dantas ${ }^{1}$ \\ Fernanda Zambon Carvalho ${ }^{1}$ \\ Debora Franceschini Mazzei ${ }^{1}$ \\ ${ }^{1}$ Universidade de Brasília, Brasília, DF, Brasil
}

\begin{abstract}
Resumo
A importância dada ao empreendedorismo na atualidade é indiscutível. Ele está relacionado com a economia dos países e com a forma como a sociedade se estrutura, No Brasil, existem mais de 50 milhões de pessoas com negócios próprios. Com essa temática de base, este artigo procura refletir sobre as questões trazidas por Jan Spruijt (2017) em seu artigo "Paradoxos do Pensamento Empresarial: por que o empreendedorismo dificilmente pode ser ensinado?" e sugerir possíveis reflexões ou mudanças na forma de atuação de universidades que contemplam disciplinas de empreendedorismo em suas grades curriculares e do Serviço de Apoio às Micro e Pequenas Empresas (SEBRAE) - em especial para algumas de suas ações educacionais - visto ser sua missão: "Promover a competitividade e o desenvolvimento sustentável dos pequenos negócios e fomentar o empreendedorismo, para fortalecer a economia nacional". O artigo foi elaborado a partir da metodologia de pesquisa exploratória de base bibliográfica e documental, com uma abordagem analítica, fazendo com que se reflita sobre as linhas de estudo que colaboram para o entendimento de Spruijt, modelos ou práticas para ensino do empreendedorismo, paradoxos do pensamento empreendedor e da prática do ensino do empreendedorismo.
\end{abstract}

Palavras-chave: Empreender. Ensino de Empreendedorismo. Pensamento Empreendedor.

\begin{abstract}
The importance given to entrepreneurship today is unquestionable. It is related to the economy of the countries and the way society is structured. In Brazil, there are over fifty million people with their own businesses. With this theme as a basis, this article seeks to reflect on the issues brought by Jan Spruijt (2017) in his article "Paradoxes of Business Thinking: why entrepreneurship can hardly be taught" and suggest possible reflections or changes in the way universities which include entrepreneurship disciplines in their curricula and also to the Brazilian Micro and Small Business Support Service (SEBRAE) - especially for some of its educational actions - as its mission is: "To promote competitiveness and the sustainable development of small businesses and to foster the entrepreneurship to strengthen the national economy". The article was elaborated from an exploratory research of bibliographic and documentary basis, with an analytical approach, leading to the reflection of the lines of study that contribute to the understanding of Spruijt, models or practices for teaching entrepreneurship, paradoxes of entrepreneurial thinking and of entrepreneurship teaching practice.
\end{abstract}

Keywords: Entrepreneurship. Entrepreneurship Teaching. Entrepreneural Thinking.

Áreas Tecnológicas: Administração de Empresas. Aval. de Sistemas, Inst. Planos e Programas Educacionais. Métodos e Técnicas de Ensino. 


\section{Introdução}

Em seu artigo, Spruijt (2017, tradução dos autores) levanta a questão sobre as dificuldades de se ensinar empreendedorismo em sala de aula. $\mathrm{O}$ autor inicia seu texto trazendo uma questão sobre o pensamento empreendedor, descrito como uma das habilidades mais relevantes para a força de trabalho do século XXI (BACIGALUPO et al., 2016 apud SPRUIJT, 2017). E, por essa razão, tornou-se um critério integral em muitos regulamentos prescritivos para educação (superior) e em números crescentes também explicitamente e implicitamente parte dos currículos (SAAVEDRA; OPFER, 2012 apud SPRUIJT, 2017).

Além disso, segundo Isenberg (2017), o fomento do empreendedorismo tornou-se um componente essencial do desenvolvimento econômico em cidades e países ao redor do mundo. A metáfora predominante para promover o empreendedorismo como estratégia de desenvolvimento econômico é o "ecossistema de empreendedorismo". O autor ressalta, no entanto, que é falsa a ideia de que se queremos ecossistemas de empreendedorismo fortes, precisamos de uma forte educação para o empreendedorismo. Hotspots empresariais bem conhecidos, como Israel, Route 128, Silicon Valley, Austin, Islândia, entre outros, apresentavam altos volumes de empreendedorismo e empreendimentos muito antes de terem cursos com a temática. Eles surgiram organicamente, acima de tudo devido ao acesso a clientes e talentos empregáveis, bem como pelo acesso ao capital. Essa constatação trazida por Isenberg (2017), apesar de não reforçar diretamente a tese de que tentar ensinar empreendedorismo é difícil, revela que é inócuo, sendo mais provável que o fenômeno ocorra naturalmente num ambiente favorável ao empreendedorismo, e não devido ao seu ensino. Uma análise do processo empreendedor, trazida por Dornelas (2016) corrobora com essa afirmativa.

Conforme ilustrado na Figura 1, o processo empreendedor apresentado por Dornelas (2016) revela uma série de fatores que vão além do simples ensino do empreendedorismo para que ele aconteça. São fatores pessoais, sociológicos, organizacionais e ambientais.

Figura 1 - Fatores que influenciam no processo empreendedor (adaptado de Moore 1986)

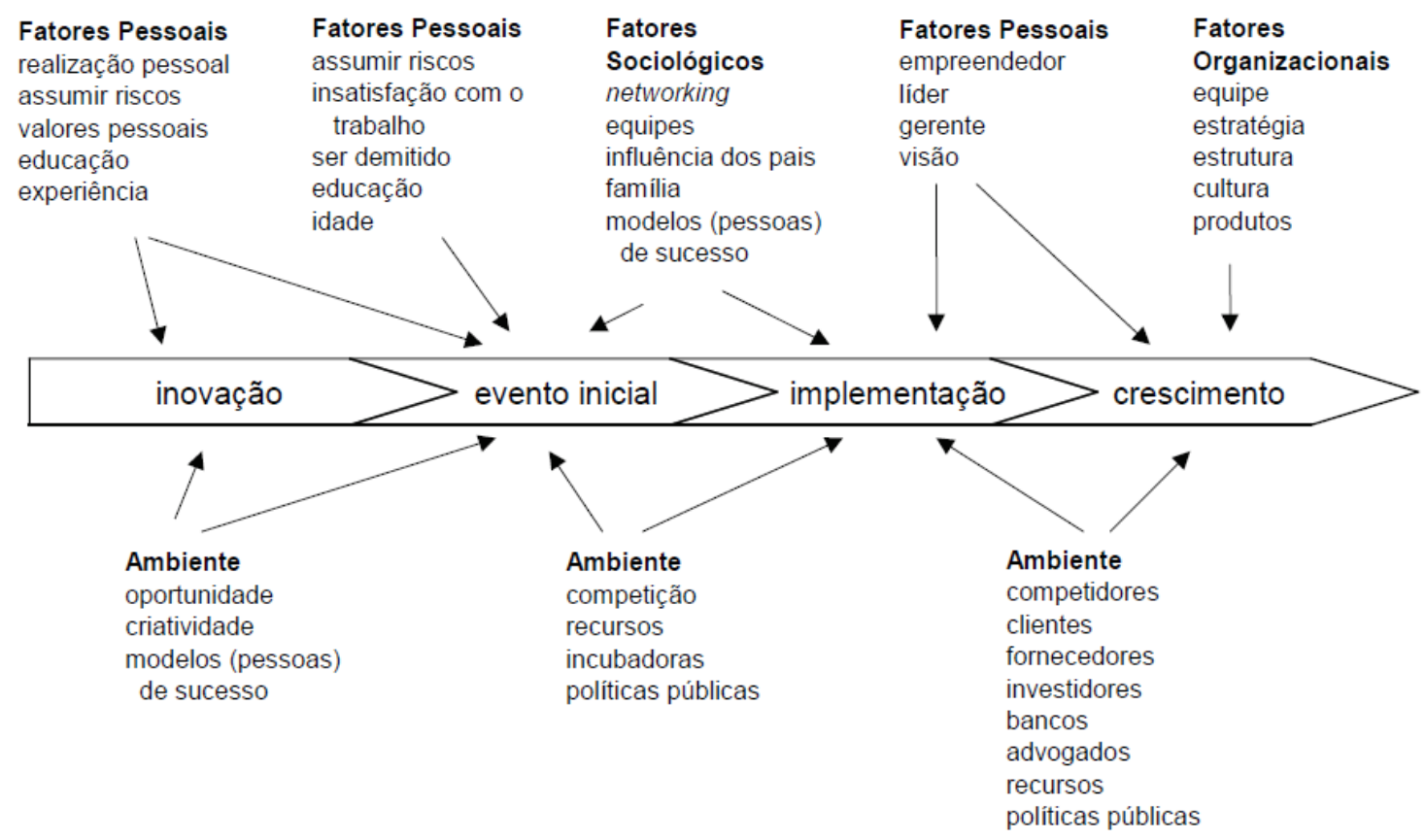

Fonte: Dornelas (2016) 
No entanto, ao contrário do empreendedorismo, o pensamento empreendedor não é necessariamente vinculado aos empresários (ou aqueles a serem); é uma habilidade essencial para "fortalecer o capital humano, empregabilidade e competitividade" (BACIGALUPO et al., 2016 apud SPRUIJT, 2017).

Segundo Spruijt (2017, p. 3), “[...] a diferença entre empreendedorismo e pensamento empreendedor reside no fato de que o empreendedorismo é sobre ações e intenções e o pensamento empreendedor é sobre atitudes e crenças". Quanto ao empreendedorismo, o autor levanta a divisão teórica que existe desde o início do debate de Schumpeter versus Kirzner. Em essência, hoje é reconhecido como a diferença entre criatividade (Schumpetariana) e alerta (Kirzneriana) ou criação versus descoberta. Na visão Schumpetariana, as oportunidades resultam da vontade interna de mudar a indústria. O empreendedor é um inovador e perturba a economia (DE JONG; MARSILI, 2010; SCHUMPETER, 1934 apud SPRUIJT, 2017). Na visão Kirzneriana, as oportunidades já estão existentes e são descobertas por empreendedores de oportunidade-alerta, estando mais ligada a uma perspectiva econômica: os empreendedores podem ver onde um bem pode ser vendido a um preço melhor que aquele para o qual pode ser comprado (BUSENITZ, 1996 apud SPRUIJT, 2017).

Essa mesma divisão acontece quando se leva em conta uma definição mais ampla de empreendedorismo, numa perspectiva mais organizacional que relaciona o empreendedorismo como "causation" (causalidade) versus "effectuation" (efetuação). Considerando que a "causation" está mais orientada para uma perspectiva gerencial, Kirzneriana, sobre o empreendedorismo, a "effectuation" é orientada para uma perspectiva mais experimental, Schumpeteriana, sobre empreendedorismo (DE JONG; MARSILI, 2010 apud SPRUIJT, 2017).

Segundo Reymen et al. (2015 apud SPRUIJT, 2017), empreendedorismo é encontrar a combinação certa entre causalidade e efetuação. Um empresário de sucesso sabe quando agir casualmente e quando agir efetivamente, quando ser criativo e quando ser gerencial. Os autores pesquisaram o número de decisões explícitas na criação de novos empreendimentos em relação a ambas as perspectivas, descritas na Figura 2:

Figura 2 - Porcentagem de dimensões de efetuação e causalidade

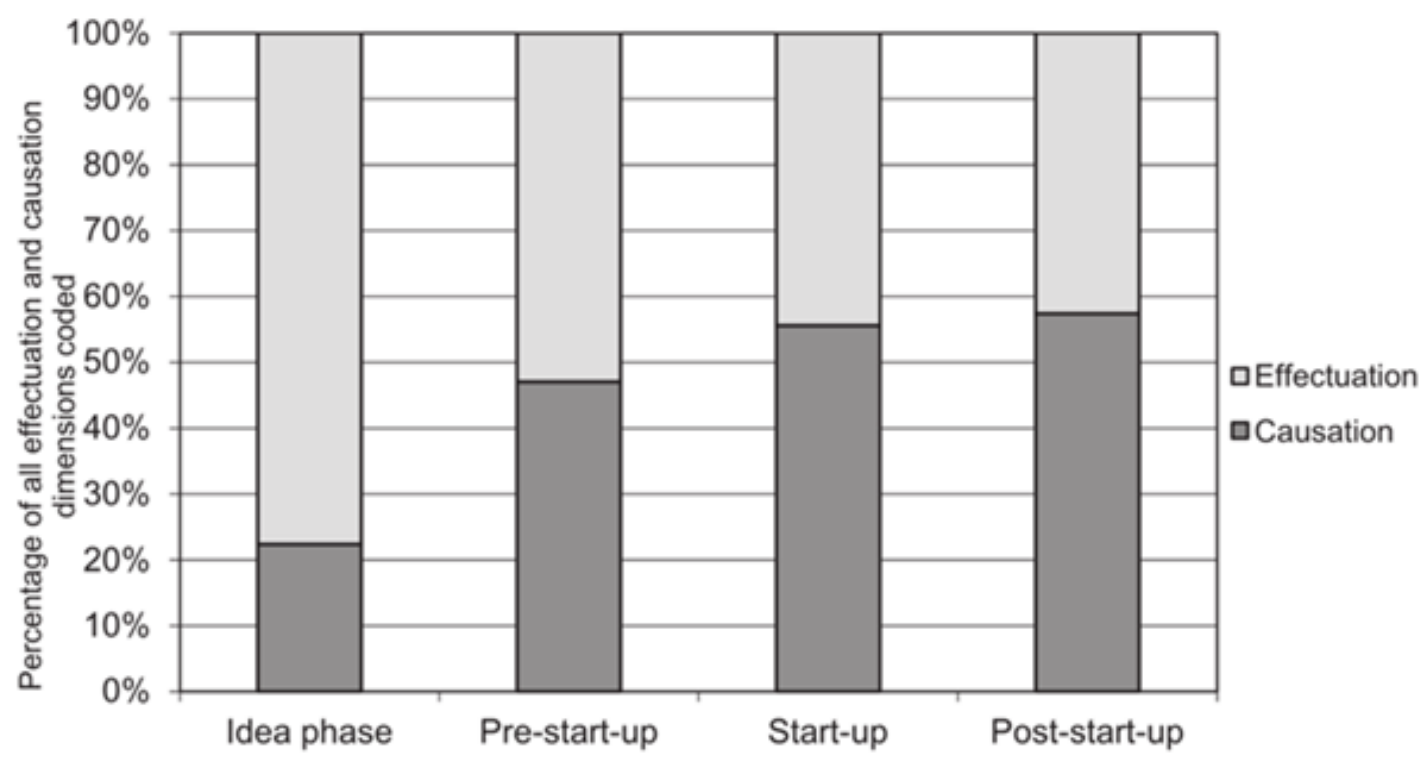

Fonte: Reymen et al. (2015 apud SPRUIJT, 2017) 
Para Spruijt (2017), o pensamento empreendedor é mais comum do que o empreendedorismo. O pensamento empreendedor concentra-se nas crenças profundas que levam a um comportamento que está positivamente relacionado ao resultado empreendedor. De uma perspectiva mais psicológica, a mesma diferença é descrita como uma mentalidade de crescimento (efetuação) versus uma mentalidade fixa (causalidade) (DWECK, 2012 apud SPRUIJT, 2017). Para Spruijt (2017), o empreendedorismo corporativo ou intraempreendedorismo são efeitos diretos do pensamento empreendedor aplicado às organizações e, em seguida, mais especificamente à cultura organizacional.

Devido à complexidade acima esboçada que desperta a natureza ambidestra do empreendedorismo, a maioria da literatura sugere que o ensino do empreendedorismo é lidar com situações paradoxais, como a incerteza. No aspecto educacional, existe uma diferença entre o ensino do empreendedorismo e o ensino sobre o empreendedorismo. Tentar desenvolver um modelo de competências em empreendedorismo é sobre o ensino do empreendedorismo.

Um exemplo de modelo que traz à tona características de comportamento empreendedor é o seminário Empretec, que é uma metodologia da Organização das Nações Unidas (ONU) voltada para o desenvolvimento de características de comportamento empreendedor e para identificação de novas oportunidades de negócios. De acordo com a página web do Empretec (SEBRAE, 2019), essa capacitação é promovida em cerca de 34 países, e no Brasil, é realizada exclusivamente pelo Serviço de Apoio às Micro e Pequenas Empresas (SEBRAE), tendo capacitado cerca de 230 mil pessoas.

Trata-se de 60 horas de capacitação em seis dias de imersão em que o participante é desafiado em atividades práticas que apontam como um empreendedor de sucesso age, considerando 10 características comportamentais, são elas:

1)Busca de oportunidade e iniciativa.

2)Persistência.

3) Correr riscos calculados.

4) Exigência de qualidade e eficiência.

5) Comprometimento.

6)Busca de informações.

7)Estabelecimento de metas.

8)Planejamento e monitoramento sistemáticos.

9) Persuasão e rede de contatos.

10) Independência e autoconfiança.

Spruijt (2017) cita uma recente publicação da Comissão Europeia sobre competência em empreendedorismo que definiu um quadro para a educação do empreendedorismo, a qual considera uma abordagem interessante, apesar de ainda não estar validada pelo fato de tentar "unir o mundo da educação e do trabalho". A Figura 3 define três áreas principais de competência: "ideias e oportunidades", "recursos" e "em ação" - e outras 15 competências (BACIGALUPO et al., 2016). 
Figura 3 - EntreComp Framework

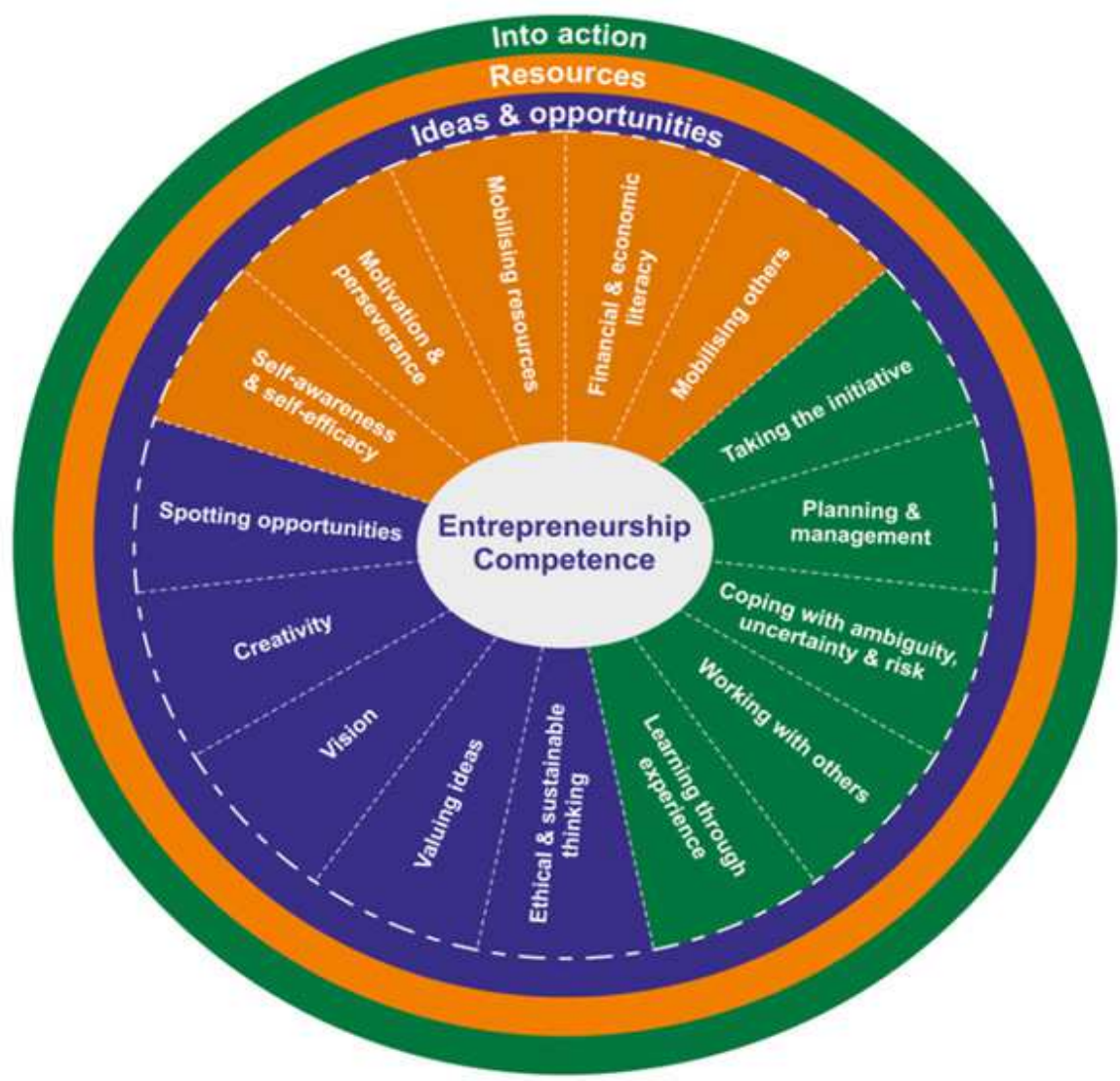

Fonte: Bacigalupo et al. (2016)

Uma outra estrutura que foi validada é a do projeto FINCODA - Framework For Innovation Competencies Development and Assessment (que poderia ser traduzido como Estrutura do Desenvolvimento e Avaliação de Competências em Inovação), apresentada na Figura 4). Embora seja um pouco mais focada em habilidades de inovação, a estrutura considera cinco competências chave para inovação e empreendedorismo: criatividade, pensamento crítico, iniciativa, trabalho em equipe e redes (MARIN-GARCIA et al., 2016 apud SPRUIJT, 2017).

Figura 4 - Framework for Innovation Competencies Development and Assessment (FINCODA)

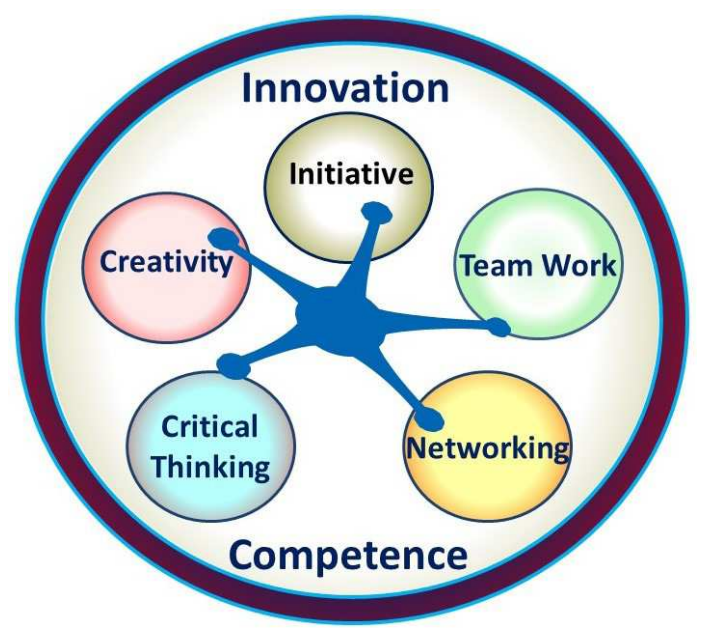

Fonte: FINCODA (2016) 


\section{Metodologia}

Este estudo está baseado na metodologia de pesquisa exploratória, uma vez que se busca entender melhor a abordagem da contestação sobre o ensino do empreendedorismo frente ao ensino do pensamento empreendedor. $\mathrm{O}$ método definido para esta pesquisa foi a análise bibliográfica e documental, tendo como texto base da análise o estudo "Paradoxos do Pensamento Empresarial: por que o empreendedorismo dificilmente pode ser ensinado", de Jan Spruijt (2017) que consolida a percepção de diversos estudiosos que convergem sobre o tema, do Programa Empretec, desenvolvido pela ONU, da atuação do Serviço de Apoio às Micro e Pequenas Empresas (SEBRAE) e de Universidades.

A abordagem analítica permitirá, ao final deste estudo, refletir sobre a nova abordagem de se ensinar sobre o pensamento empreendedor e a atuação de universidades que contemplam disciplinas de empreendedorismo em suas grades curriculares e do SEBRAE - em especial para algumas de suas ações educacionais que buscam ensinar pessoas a empreender.

\section{Resultados e Discussão}

Mesmo ao saber quais as competências que deveriam ser ensinadas para aumentar o sucesso empresarial em um cenário complexo e paradoxal como o que é vivido atualmente, poderia se imaginar como ensinar essas competências de um ponto de vista mais didático. Neck et al. (2014 apud SPRUIJT, 2017, tradução dos autores) argumentam que a "[...] ação efetiva do empreendedorismo requer um conjunto de práticas e essas práticas estão firmemente fundamentadas em teoria". Eles chamam essa aprendizagem de teoria acionável, conforme descrito na matriz exposta na Figura 5.

Figura 5 - A matriz teoria-prática.

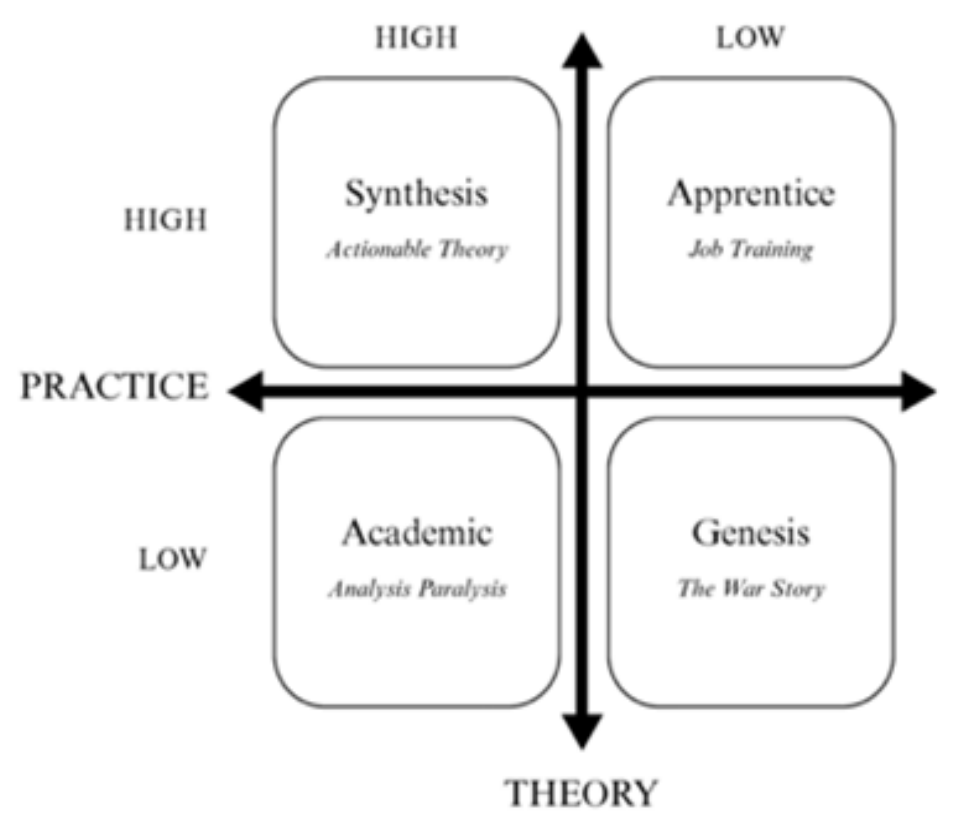

Fonte: Neck et al. (2014 apud SPRUIJT, 2017) 
Os autores argumentam que existem cinco práticas diferentes de ensinar empreendedorismo, conforme apresentado na Figura 6:

a)Prática do jogo: "[...] a habilidade do jogo liberta a imaginação, abre a nossa mente a uma grande quantidade de oportunidades e possibilidades, e nos ajuda a ser mais inovadores como empreendedores" (NECK; NECK; MURRAY, 2017 apud SPRUIJT, 2017, p. 5, tradução dos autores). O jogo inclui o uso de jogos de simulação que desafiam a pensar como empreendedor.

b) Prática de Experimentação: "[...] a habilidade de jogo é melhor descrita como atuação para aprender - tentar algo, aprender com a tentativa e construir esse aprendizado na próxima iteração" (NECK et al., 2017 apud SPRUIJT, 2017, p. 6, tradução dos autores).

c) Prática de Empatia: pode ser ensinado usando métodos criativos de pesquisa. (SPRUIJT, 2017, tradução dos autores).

d) Prática de Criatividade: pode ser ensinado usando técnicas e métodos criativos, como o design thinking (NECK et al., 2017 apud SPRUIJT, 2017, tradução dos autores).

e) Prática de Reflexão: pode ser ensinado usando diferentes modos de reflexão em sala de aula, tais como reflexão narrativa, reflexão emocional, reflexão analítica e reflexão crítica. Embora os benefícios tenham sido amplamente suportados, a reflexão não é concretizada, levada à prática (NECK et al., 2017 apud SPRUIJT, 2017, tradução dos autores).

Figura 6 - As práticas de educação para empreendedorismo

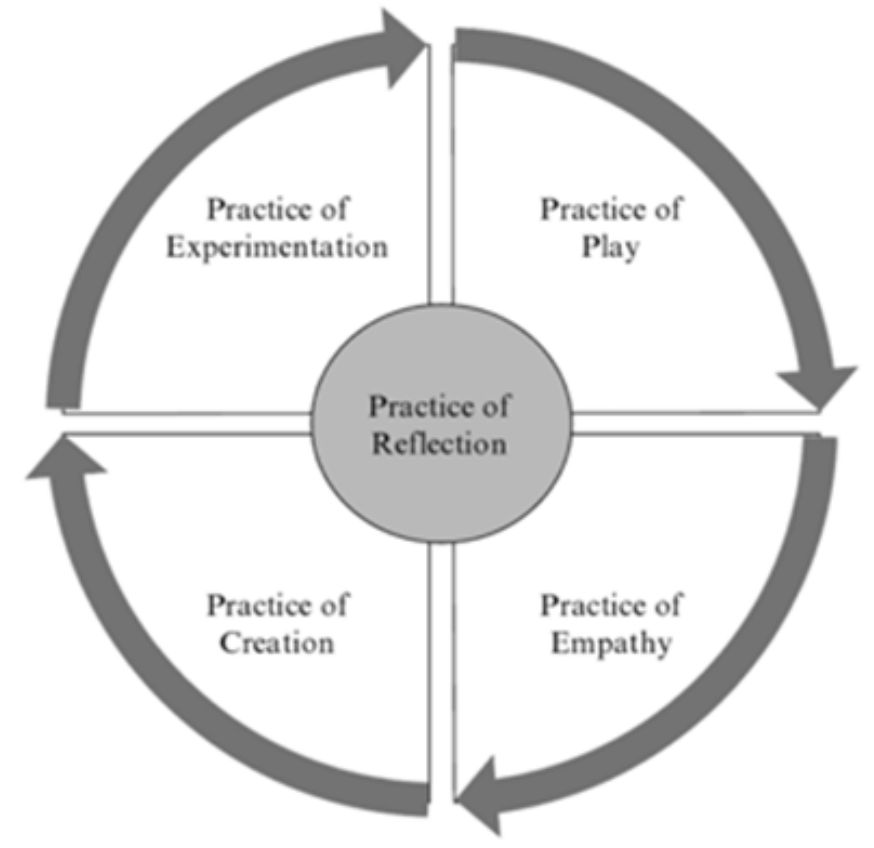

Fonte: Neck et al. (2014 apud SPRUIJT, 2017)

Muitos programas educacionais seguem a regra de ouro das primeiras competências definidoras e seu corpo de conhecimento, habilidades e atitudes, que então conduzem a objetivos de currículo, ensino e aprendizagem que podem ser avaliados, examinados e constituindo a base do material de aprendizagem (BIGGS, 1996; BROWN, 1995 apud SPRUIJT, 2017). Isso acontece, inclusive com alguns programas do Sebrae e com alguns cursos que tratam da temá- 
tica do empreendedorismo. Esses objetivos são uma parte essencial da educação. Eles são mais específicos do que competências, mas geralmente não leva em conta a natureza ambidestra do empreendedorismo.

Lidar com a ambiguidade, a causalidade e a efetuação, é como tentar resolver uma equação insolúvel. Ou como Ludwig van Mises escreveu: "Os empreendedores desafiam quaisquer regras e sistematização. [Empreendedorismo] não pode ser ensinado nem aprendido" (KLEIN; BULLOCK, 2006; LEWIN, 2011; VON MISES, 1949 apud SPRUIJT, 2017, p. 7)

A literatura mais recente, no entanto, sugere que o empreendedorismo possa ser aprendido, mas ainda não pode ser ensinado.

Alguns professores de negócios sonham em encontrar um grande algoritmo que lhes permita orientar decisões empresariais e julgar antecipadamente quais decisões são boas e quais são ruins. [Isso foi revelado como] uma forma de pensamento mágico. Precisamos que os empresários tomem suas decisões por si mesmos precisamente porque é impossível para nós tomar essas decisões por eles. (KOPPL, 2008; LEWIN, 2011 apud SPRUIJT, 2017, p. 7)

Spruijt (2017) propõe um conjunto de objetivos de ensino, baseado em paradoxos a serem abordados, que sejam construídos de forma a lidar com o dilema que surgiu na literatura Kirzneriana e Schumpetariana sobre empreendedorismo e seguindo a linha de práticas conforme proposto por Neck et al. (2014). São eles:

\section{\# 1: o Paradoxo da Incerteza}

Este paradoxo foi enquadrado por Lewin (2011 apud SPRUIJT, 2017, p. 7) em um artigo interessante denominado Paradoxos Empresariais, como segue: "as oportunidades empresariais são complicadas pela incerteza, mas não existirão sem incerteza".

\section{\# 2: o Paradoxo Estratégico}

Este paradoxo específico está intimamente relacionado com a ambidestreza organizacional, que trata da dificuldade entre investigação e exploração de oportunidades: para um modelo de negócios sustentável a longo prazo, um empresário precisaria se concentrar na investigação, mas sua empresa não seria capaz de sustentar-se sem uma estratégia de exploração a curto prazo. Isso também é referido como a escolha entre pivotar ou perseverar (RIES, 2011 apud SPRUIJT, 2017).

\section{\# 3: o Paradoxo da Oportunidade}

Este é um paradoxo complicado, mas basicamente descreve a maneira fundamental pela qual os empresários veem e reconhecem oportunidades. Por um lado, as oportunidades podem existir e serem descobertas - como foi descrito anteriormente no artigo - mas, por outro lado, pode-se afirmar que as oportunidades são criadas e exploradas. Este paradoxo é questionável, no entanto, porque se poderia imaginar que uma oportunidade criada por um empreendedor específico já não era realmente uma oportunidade existente perdida por alguém (LEWIN, 2011 apud SPRUIJT, 2017).

\section{\# 4: o Paradoxo da Experiência}

Este é bastante simples de entender: um empreendedor nunca poderia ter experiência suficiente para sempre fazer decisões sábias em retrospectiva. Um empresário prefere basear suas decisões na experiência anterior, ainda que não reflita completamente a situação atual. 


\section{\# 5: o Paradoxo do Momento}

Quando confrontado com uma decisão mais complexa, muitas vezes surge o dilema se eu fizer isso agora, será muito cedo para o mercado, ou se eu esperar, será muito tarde para o meu negócio? Escolher o momento certo para a decisão certa é muitas vezes paradoxal, porque um empresário agirá muito cedo, se ninguém mais agir cedo demais, agirá na hora certa, quando alguém tiver agido cedo demais e agirá tarde demais se todos os outros tiverem agido antes.

\section{\# 6: o Paradoxo de Generalização}

Por incrivel que pareça, há mais literatura sugerindo que um empresário se caracteriza pelo fato de que seus traços de personalidade são únicos do que qualquer outra pessoa, tornando assim impossível descrever um conjunto geral de competências, habilidades ou ações comportamentais. Ou como Lewin (2011 apud SPRUIJT, 2017, p. 8) diz: "Os elementos da categoria empreendedor são todos indivíduos únicos cujas características (quase) desafiam a generalização". Um empreendedor deve, portanto, sempre se perguntar se ele deve aprender com as melhores práticas de outros empresários, ou que ele deve aprender com outros empresários de uma maneira que propositalmente não queira copiar suas melhores práticas.

\section{\# 7: o Paradoxo de tomada de decisão}

A restrição simples do tempo e orçamento limitados constitui a espinha dorsal de quase todas as decisões tomadas nos negócios.

\section{\# 8: o Paradoxo do Impacto}

A maioria dos empreendedores tem que lutar continuamente entre tentar criar impacto social com seus negócios ou tentar ter impacto econômico em seus negócios.

\section{\# 9: Paradoxo de risco}

O risco é um dos elementos mais pesquisados do empreendedorismo. Na prática, cada empresário se perguntará repetidas vezes: vale a pena correr o risco (ainda que calculado) ou não?

\section{\# 10: Paradoxo do conhecimento}

Um empresário não tem tempo, nem tem a intenção, de conhecer todas as informações que ele pode usar para tomar decisões efetivas para sua empresa. O chamado "hiato do conhecimento" é predominante nas ações do dia a dia e o empreendedor encontra-se escolhendo entre aprender e fazer.

\section{\# 11: Paradoxo da confiança}

Como um empreendedor não poderá conhecer tudo ele mesmo, o paradoxo do conhecimento, ele se encontra confiando em outras informações. Isso levanta a questão: ele pode confiar nas informações que ele recebe? O paradoxo de confiança é visível ao lidar com pessoas de fora, colaboradores, clientes, fornecedores, etc., e é de grande dificuldade para empresários

Para Spruijt (2017), o empreendedorismo, tanto quanto o pensamento empreendedor, não podem ser ensinados, mas pode-se ensinar a tolerância à ambiguidade e, com isso, uma autorreflexão necessária para emplacar o pensamento empresarial de forma autodidata. Para ensinar a tolerância para a ambiguidade, os professores precisam lidar com os paradoxos acima 
mencionados, em vez de tentar traduzi-los em material didático. Isso torna a aprendizagem em empreendedorismo mais tácita do que explícita.

A criação de empresas por si só não leva ao desenvolvimento econômico, a não ser que esses negócios estejam focando oportunidades no mercado. Isso passou a ficar claro a partir do estudo anual do Global Enterpreneurship Moniror (GEM), do qual originaram-se duas definições de tipos de empreendedorismo. A primeira seria o empreendedorismo de oportunidade, em que o empreendedor visionário sabe aonde quer chegar, cria uma empresa com planejamento prévio, tem em mente o crescimento que quer buscar para a empresa e visa à geração de lucros, empregos e riqueza. Está totalmente ligado ao desenvolvimento econômico, com forte correlação entre os dois fatores (DORNELAS, 2016).

A segunda definição seria o empreendedorismo de necessidade, em que o candidato a empreendedor se aventura na jornada empreendedora mais por falta de opção, por estar desempregado e não ter alternativas de trabalho. Nesse caso, esses negócios costumam ser criados informalmente, não são planejados de forma adequada e muitos fracassam bastante rápido, não gerando desenvolvimento econômico e agravando as estatísticas de criação e mortalidade dos negócios. Esse tipo de empreendedorismo é mais comum em países em desenvolvimento, como ocorre com o Brasil, e também influencia na atividade empreendedora total desses países. Assim, não basta o país estar ranqueado nas primeiras posições do GEM. O que o país precisa buscar é a otimização do seu empreendedorismo de oportunidade (DORNELAS, 2016).

Essa divisão do empreendedorismo em dois tipos criada pelo GEM - por oportunidade e por necessidade - também se enquadra nos paradoxos levantados por Spruijt. Afinal, se um potencial empreendedor está desempregado, ele pode se empenhar mais em identificar oportunidades de empreender que uma pessoa empregada que, ao mesmo tempo, pode perder oportunidades por não necessitar empreender para obter renda.

Isso pode ser melhor entendido pelo texto do Isenberg (2017), em que ele afirma que é falsa a informação que há um forte ecossistema de empreendedorismo quando há um número crescente de startups, tipicamente citadas como casos de empreendedorismo de oportunidade. Segundo o autor, não há evidências de que apenas aumentar o número de startups ou formar novos negócios estimule o desenvolvimento econômico. Há alguma evidência do contrário, ou seja, o crescimento econômico estimula a criação de novos negócios e startups. Há também alguns motivos para acreditar que o número de pequenas empresas está relacionado negativamente com a saúde econômica nacional. A Fundação Kauffman informou recentemente que, à medida que a economia dos EUA melhora e o emprego de qualidade aumenta, o número de startups diminui. Na verdade, incentivar startups pode ser uma má política. Nota-se que o autor não menciona empreendedorismo por oportunidade ou necessidade, mas a condição econômica favorável ou não, sugerindo que o ambiente favorável é mais determinante que a condição do empreendedor em si e não o contrário.

\section{Considerações Finais}

Se for de fato mais fácil aprender empreendedorismo do que ensinar, como sugere Spruijt (2017), talvez seja mais efetivo por parte do SEBRAE e outras organizações que trabalham com ensino de empreendedorismo agir em duas frentes principais a fim de fomentar o empreendedo- 
rismo: ajudar a criar um ambiente mais favorável ao empreendedorismo, por meio de ações junto ao governo (políticas mais favoráveis à formação e desenvolvimento de empresas), e desenvolver soluções educacionais em empreendedorismo que promovam as cinco práticas sugeridas por Neck et al. (2017). Além disso, cabe uma reflexão sobre os paradoxos do empreendedorismo, ou seja, treinar o pensamento empreendedor mais do que empreendedorismo em si. Este seria consequência, se e quando houver um ambiente favorável.

Ou seja, deve-se entender o empreendedorismo como sendo um "efeito emergente" desse ambiente favorável, em que os potenciais empresários a serem treinados - e não capacitados - pelo SEBRAE e outras organizações envolvidas no ecossistema em práticas empreendedoras $e$ aptos a lidar com os paradoxos citados sejam capazes de identificar as oportunidades (Visão Kirzneriana - Causation) ou criar novas oportunidades de negócios (visão Schumpeteriana Effectuation) quando acharem conveniente e favorável, considerando os diversos fatores do processo empreendedor.

\section{Referências}

BACIGALUPO, Marguerita et al. EntreComp: the entrepreneurship competence framework. EUR - Scientific and Technical Research Reports. Publications Office of the European Union, 2016. Disponível em: https://ec.europa.eu/jrc/en/publication/eur-scientific-and-technical-research-reports/ entrecomp-entrepreneurship-competence-framework. Acesso em: 28 ago. 2019.

BAGGIO, Adelar Francisco; BAGGIO, Daniel Knebel. Empreendedorismo: Conceitos e definições. Revista de Empreendedorismo, Inovação e Tecnologia, Passo Fundo, v. 1, n. 1, p. 25-38, jan. 2015. ISSN 2359-3539. Disponível em: https://seer.imed.edu.br/index.php/revistasi/ article/view/612/522. Acesso em: 5 ago. 2019.

DORNELAS, José Carlos Assis. O processo empreendedor. In: DORNELAS, José Carlos Assis. Empreendedorismo: transformando ideias em negócios. 6. ed. São Paulo: Atlas, 2016. p. 7-37.

SEBRAE - SERVIÇO BRASILEIRO DE APOIO ÀS MICRO E PEQUENAS EMPRESAS. Página web do Empretec: fortaleça suas habilidades como empreendedor. [2019]. Disponível em: http://www. sebrae.com.br/sites/PortalSebrae/sebraeaz/empretec-fortaleca-suas-habilidades-como-empreendedor, db3c36627a963410VgnVCM1000003b74010aRCRD. Acesso em: 5 ago. 2019.

FINCODA - FRAMEWORK FOR INNOVATION COMPETENCIES DEVELOPMENT AND ASSESSMENT. O projeto FINCODA: 2015-2017. [2016]. Disponível em: https://www.fincoda.eu/. Acesso em: 28 ago. 2019.

ISENBERG, Daniel. Como é na realidade um ecossistema de empreendedorismo. 2017. Disponível em: http://hbrbr.uol.com.br/como-e-na-realidade-um-ecossistema-de-empreendedorismo/. Acesso em: 5 ago. 2019.

SPRUIJT, Jan. Paradoxes of Entrepreneurial Thinking: why entrepreneurship can hardly be taught. 2017. Disponível em: file:///C:/Users/patyc/Downloads/SSRN-id2969895.pdf. Acesso em: 6 ago. 2019. 


\section{Sobre os Autores}

\section{Sônia Marise Salles Carvalho}

E-mail: smarises1960@gmail.com

Doutorado.

Endereço profissional: Universidade de Brasília, Campus Universitário Darcy Ribeiro Edifício CDT, Brasília, DF. CEP: 70904-970.

\section{Adriana Regina Martin}

E-mail: drimartin88@gmail.com

Doutorado.

Endereço profissional: Ministério da Ciência, Tecnologia, Inovações e Comunicações, SETEC. Esplanada dos Ministérios, Brasília, DF. CEP: 70067-900.

\section{Agnaldo Almeida Dantas}

E-mail: agnaldoadantas@gmail.com

Mestrado.

Endereço profissional: Sebrae Nacional, Conjunto A, SGAS 605, Brasília, DF. CEP: 70200-904.

\section{Fernanda Zambon Carvalho}

E-mail:nanda.zc@gmail.com

Mestrado.

Endereço profissional: Sebrae Nacional, Conjunto A, SGAS 605, Brasília, DF. CEP: 70200-904.

\section{Debora Franceschini Mazzei}

E-mail: debora.dfmazzei@gmail.com

Mestrado.

Endereço profissional: Sebrae Nacional, Conjunto A, SGAS 605, Brasília, DF. CEP: 70200-904. 